\title{
Detailed assessment of climate variability in the Baltic Sea area for the period 1958 to 2009
}

\author{
Andreas Lehmann*, Klaus Getzlaff, Jan Harlaß \\ Leibniz Institute of Marine Sciences, University of Kiel, Düsternbrooker Weg 20, 24105 Kiel, Germany
}

\begin{abstract}
The warming trend for the entire globe (1850 to 2005) is $0.04^{\circ} \mathrm{C}$ decade $^{-1}$. A specific warming period started around 1980 and continues until the present. This warming also occurred in the Baltic Sea catchment, which lies between maritime temperate and continental subarctic climate zones. A detailed study of climate variability and the associated impact on the Baltic Sea area for the period 1958 to 2009 revealed that the recent changes in the warming trend are associated with changes in large-scale atmospheric circulation over the North Atlantic. The number and pathways of deep cyclones changed considerably in line with an eastward shift of the North Atlantic Oscillation centers of action. There is a seasonal shift of strong wind events from autumn to winter and early spring. Since the late 1980s, the winter season (DJFM, i.e. December to March) of the Baltic Sea area has tended to be warmer, with less ice coverage and warmer sea surface temperatures, especially pronounced in the northern parts of the Baltic Sea. There is a tendency for increased cloud cover and precipitation in regions that are exposed to westerlies and less cloud coverage at the leeward side of the Scandinavian Mountains and over the Baltic Sea Basin.
\end{abstract}

KEY WORDS: Baltic Sea $\cdot$ NAO $\cdot$ Climate variability

Resale or republication not permitted without written consent of the publisher

\section{INTRODUCTION}

The warming trend for the entire globe (1850 to $2005)$ is $0.04^{\circ} \mathrm{C}$ decade $^{-1}$. A specific warming period started around 1980 and continued at least until 2005, with a temperature increase of about $0.17^{\circ} \mathrm{C}$ decade $^{-1}$. This trend is equally evident for many areas on the globe, especially in the northern hemisphere in observations and climate simulations (Trenberth et al. 2007). For the Baltic Sea catchment, which lies between maritime temperate and continental subarctic climate zones, an even stronger warming of about $0.4^{\circ} \mathrm{C}$ decade $^{-1}$ has occurred since 1980. The Baltic Sea is one of the largest brackish seas in the world. It is a semienclosed basin of estuarine character with a total area of $415000 \mathrm{~km}^{2}$ and a volume of $21700 \mathrm{~km}^{3}$ (Fig. 1). The Baltic Sea is highly dynamic and strongly influenced by large-scale atmospheric circulation, hydrological processes in the catchment area, and restricted water exchange with the North Sea through the narrow and shallow transition zone between both seas (for details see Leppäranta \& Myrberg 2009).
From 1960 to 1980 the annual mean air temperature for the Baltic Sea catchment was close to or slightly below the long-term mean for the period 1871 to 2004 , and only between 1965 and 1975 was the temperature slightly above the mean. From the beginning of the 1980s, the annual mean temperature increased by about $1^{\circ} \mathrm{C}$ until 2004 (BACC Author Group 2008, their Fig. 2.4). A similar warming trend was observed for the sea surface temperature (SST) of the Baltic Sea (Siegel et al. 2006, MacKenzie \& Schiedek 2007). Since 1985, summer SSTs have increased at nearly triple the global warming trend, and for the period 1985 to 2002 summer SSTs have risen by $1.4^{\circ} \mathrm{C}, 2$ to 5 times faster than in any other season. Even the annual mean water temperatures averaged spatially and vertically for the deep basins of the Baltic Sea show similar trends (Hinrichsen et al. 2007).

The long-term record of surface air temperature (SAT) observations at Hamburg-Fuhlsbüttel, Germany $\left(53^{\circ} 38^{\prime} \mathrm{N}\right.$, 9 ${ }^{\circ} 59^{\prime} \mathrm{E}$; hereinafter called ' $\mathrm{HT}^{\prime}$ for Hamburg time series) for the period 1892 to 2009 gives a good representation of the air temperature of the 


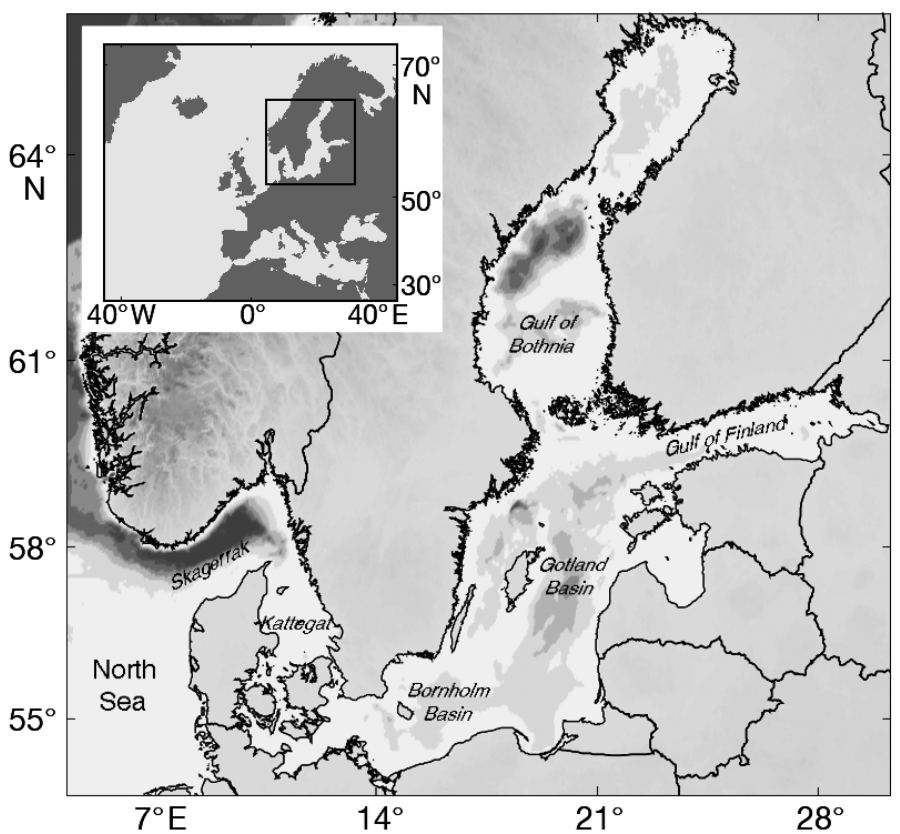

Fig. 1. Map of the Baltic Sea area

whole Baltic Sea area. Correlation coefficients for the seasonal mean air temperature between HT and different sub-basins range from 0.8 to 0.9 (statistically significant, $\mathrm{p}<0.05$ ), thus representing well the temperature evolution of the Baltic Sea area. Additionally, the winter (DJFM, i.e. December to March) air temperature anomalies of HT correlate well with the North Atlantic Oscillation (NAO) winter (DJFM) index (correlation coefficient of $0.7, \mathrm{p}<0.05$ ) for the whole period 1892 to 2009 (Fig. 2). For high $\mathrm{NAO}^{+}$conditions, the NAO spatial correlation length scale, which describes the area of influence of the westerlies, is well extended to northern Europe, while for low $\mathrm{NAO}^{+}$or $\mathrm{NAO}^{-}$conditions, its impact decreases and the continental influence on climate variability increases (Hurrell 1995).
Thus, positive temperature anomalies scale quite well with the strength of the NAO indices, while this is not the case for negative temperature anomalies (Chen \& Hellström 1999, Lehmann et al. 2002). The number of anomalous warm winters has greatly increased for the period 1988 to 2009; e.g. the winter 2006/07 was about $4^{\circ} \mathrm{C}$ warmer than the seasonal mean over the period 1892 to 2009. The winters over the last 2 decades were not only mild in the southwestern Baltic area, but the maximum sea-ice extent (MIB) (Seinä \& Palosuo 1996) was, with a few exceptions, below the average of $186640 \mathrm{~km}^{2}$ (Fig. 3). During winter 2007/08, a new low ice record was documented, with a maximum ice cover of only about $49000 \mathrm{~km}^{2}$, which is the smallest ice cover since 1720 (Vainio \& Isemer 2008). Linear correlation analysis between the NAO index (DJFM) and the time series of MIB (1892 to 2009) revealed a correlation coefficient of $-0.57(\mathrm{p}<0.05)$. Omstedt \& Chen (2001) demonstrated that the relationship between the NAO index and MIB is not constant over time. Changes in this relationship have been explained by examining changes in the location of atmospheric pressure patterns (Koslowski \& Loewe 1994).

The influence of the NAO on temperature over the Baltic area and the sea ice extent has been the subject of a number of studies. The impact of the NAO on regional temperature variability in Sweden (Chen \& Hellström 1999) and on sea ice conditions of the Baltic Sea (Koslowski \& Loewe 1994, Koslowski \& Glaser 1999) has been studied, and statistically significant relationships have been found between the ice extent, changes in air temperature, and large-scale atmospheric circulation (Tinz 1996, Omstedt \& Chen 2001).

As climate, to a large extent, controls patterns of water circulation and biophysical aspects relevant for biological production, such as the vertical distribution of temperature and salinity, alterations in climate may severely impact the trophic structure and functioning

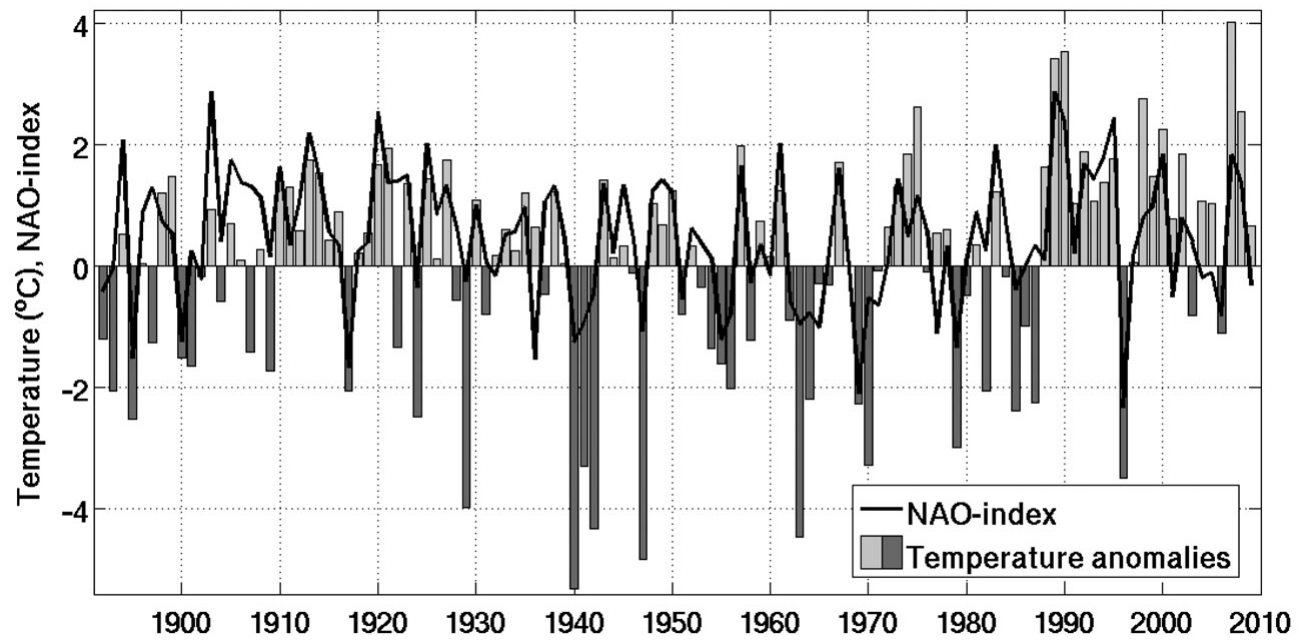

Fig. 2. Winter (DJFM) surface air temperature anomalies with respect to the longterm average (1892 to 2009) at Hamburg-Fuhlsbüttel, Germany (bars), and the North Atlantic Oscillation (NAO) winter (DJFM) index for the same period 
Fig. 3. Anomalies of the maximum sea-ice extent of the Baltic Sea (1892 to 2009) with respect to the long-term mean $\left(186640 \mathrm{~km}^{2}\right)$, based on sea-ice data collected by the Finnish Meteorological Institute

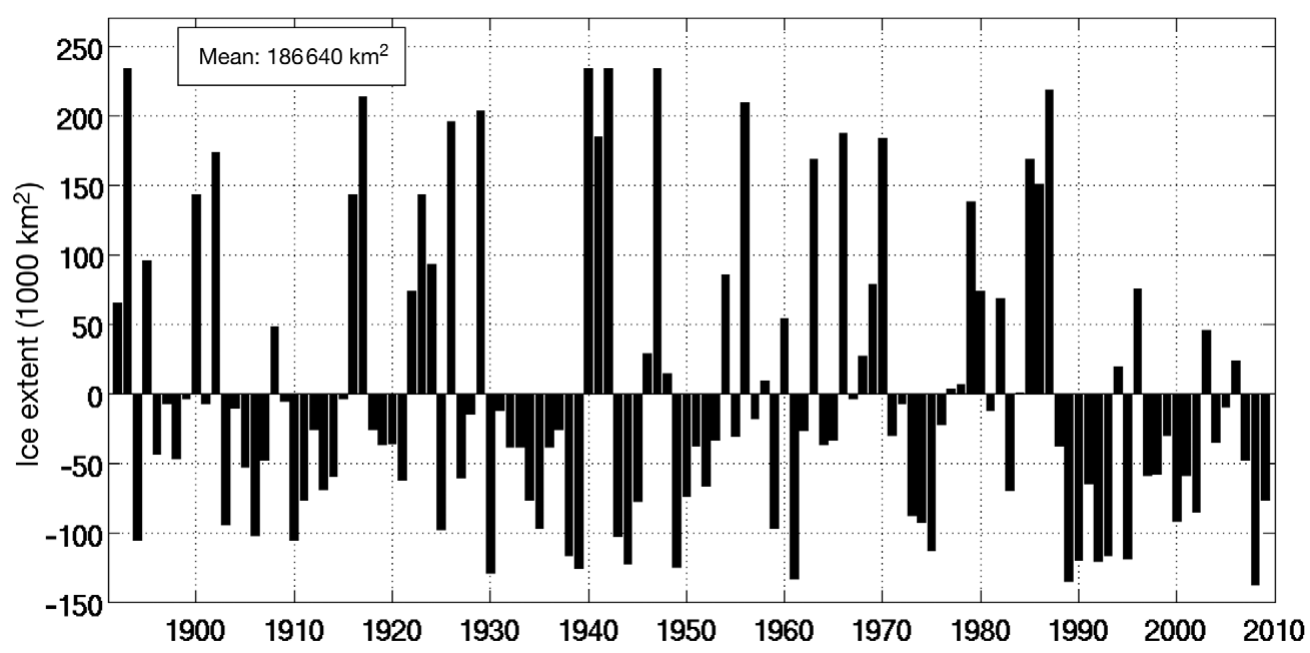

of marine food webs. Since the mid-1980s an acceleration in climate warming has occurred that agrees remarkably well with a regime shift in pelagic food webs (e.g. Hinrichsen et al. 2007).

The climate of the Baltic Sea region together with climate scenarios and climate impact on the Baltic Sea up to the year 2100 has been thoroughly reviewed by the BALTEX Assessment of Climate Change (BACC) team (BACC Author Group 2008). In the present study we provide a detailed analysis of climate variability and associated changes in the Baltic Sea area for the period 1958 to 2009, during which the recent acceleration of climate warming happened. The focus of the present study is on the assessment of climate change and not on the attribution either by human activity or natural variability.

Of course the period is too short to discriminate between changes related to climate change and those related to decadal variability. The main questions we would like to address are: Can we detect similar changes, such as those seen in mean air temperature, in other atmospheric variables? Are these changes related to changes in large-scale atmospheric circulation?

This knowledge will be needed to be able to assess whether future climate data show a continuation of recent variability and trends or show extreme cases. It will also be needed to help assess the inherent variability in climate models.

\section{DATA AND METHODOLOGY}

The detailed analysis of climate variability is based on the National Centers for Environmental Prediction (NCEP) and National Center for Atmospheric Research (NCAR) reanalysis (hereinafter NNR) data (Kalnay et al. 1996) provided by the Physical Sciences Division of NOAA's Earth System Research Laboratory (www. esrl.noaa.gov/psd) covering the northern hemisphere for the period 1948 to 2009. However, NNR data are poorly resolved $\left(2.5 \times 2.5^{\circ}, 6 \mathrm{~h}\right)$ for the Baltic Sea area. Thus, we additionally used atmospheric data from the Swedish Meteorological and Hydrological Institute $(\mathrm{SMHI})$ meteorological database $\left(1 \times 1^{\circ}, 3 \mathrm{~h} ; 1970\right.$ to 2008; L. Meuller pers. comm.) together with SST data (1990 to 2008) from the Federal Maritime and Hydrographic Agency, Hamburg (BSH) and long-term SAT records (1892 to 2009) of HT provided by the German Weather Service (www.dwd.de; station code 10147). The time series of the NAO index, as defined in Jones et al. (1997), was taken from the University of East Anglia's Climatic Research Unit database (www.cru. uea.ac.uk/cru/data/nao). Leibniz Institute of Marine Sciences (IFM-GEOMAR) meteorological observations

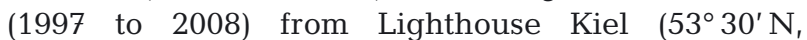
$10^{\circ} 16.5^{\prime}$ E) located in Kiel Bight, western Baltic Sea, were used to validate SMHI meteorological data. The mean difference in daily mean air temperature between the 2 data sets was $<1^{\circ} \mathrm{C}$, and daily mean wind speed differed by $1.4 \mathrm{~m} \mathrm{~s}^{-1}$ with a deviation in wind direction of $6^{\circ}$. A detailed comparison of SMHI meteorological data with observations has been performed by Rudolph \& Lehmann (2006). Rutgersson et al. (2001) compared SMHI precipitation data with estimates based on NOAA's Comprehensive Ocean Atmosphere Data Set (COADS) and showed that both data sets agree very well. However, the SMHI data may underestimate precipitation, because of the neglect of the rain gauges flow distortion and evaporation error correction.

Besides linear regression and correlation, we used wavelet analysis to examine the connection between mean winter season air temperature anomalies of HT and NAO indices and especially to explore the phase relationship and their common features. Wavelet spec- 
tra are based on Morlet wavelets calculated as described in Torrence \& Compo (1998). To analyze largescale atmospheric sea level pressure (SLP) patterns, especially the NAO, which is a large contributor to the climate variability of northern Europe, empirical orthogonal function (EOF) (or principal component) analysis was performed. In this approach the NAO is identified from the eigenvectors of the covariance matrix computed from the time variations of the grid point values of SLP. The eigenvectors, each constrained to be spatially and temporally orthogonal to the others, are then scaled according to the amount of total data variance they explain. A well-known shortcoming of EOF analysis is that the eigenvectors are mathematical constructs, constrained by their mutual orthogonality and the maximization of variance over the entire analysis domain. Therefore, the pattern structure of any particular EOF must be interpreted with care (e.g. Dommenget \& Latif 2002). Jung et al. (2003) performed an EOF analysis of NNR SLP data for the period 1958 to 1997 over separated time windows, 20 yr each. We followed this approach and calculated EOFs for the period 1958 to 2008 using 20 yr time windows, each overlapping by 10 yr (P1: 1958-1977, P2: 1968-1987, P3: 1978-1997, P4: 1988-2007) applied over the spatial window $100^{\circ} \mathrm{W}$ to $100^{\circ} \mathrm{E}$ and 10 to $90^{\circ} \mathrm{N}$. The first EOF for each of the periods is well separated from subsequent modes; thus, according to the criterion of North et al. (1982), we are confident that the first EOF represents the NAO pattern. Hurrell \& Deser (2009) pointed out that there is no unique way to define the NAO. In contrast to linear techniques, which assume that preferred atmospheric circulation states come in pairs, nonlinear techniques search for recurrent patterns of a specific amplitude and sign. Therefore, we additionally included a cluster analysis as a nonlinear technique, applied to the winter (DJFM) daily mean SLP anomalies from NNR data for the period 1949 to 2009 over the Atlantic domain $\left(20\right.$ to $80^{\circ} \mathrm{N}, 80^{\circ} \mathrm{W}$ to $\left.30^{\circ} \mathrm{E}\right)$. We analyzed the dominant regimes during the $20 \mathrm{yr}$ periods (P1, P2, P3, and P4) for the winter (DJFM) seasons.

\section{RESULTS}

\subsection{Large-scale atmospheric variability}

The climate of the Baltic Sea area is controlled by large pressure systems that govern the air flow over the continent: the Icelandic Low, the Azores High, and the winter high/summer low over Russia. The NAO is a circulation factor strongly influencing the climate of Europe, and its influence is strongest during the winter months (Hurrell \& van Loon 1997). From cluster analysis applied over the Atlantic domain, Hurrell \& Deser
(2009) identified 4 winter climate regimes in daily SLP. Two of them correspond to the negative and positive phases of the NAO, while the third and fourth regimes display strong anticyclonic ridges over Scandinavia and eastern Europe (the 'Blocking' regime) and off western Europe (the 'Atlantic Ridge' regime). The latter bears some resemblance to the East Atlantic pattern as described by e.g. Wallace \& Gutzler (1981). All 4 regimes occurred with approximately the same frequency on between 21 and $29 \%$ of all winter days (DJFM) over the period 1950 to 2006. However, the most prominent index used to characterize the largescale atmospheric variability over northern Europe and especially the Baltic area is the NAO.

EOF analysis was applied to winter (DJFM) monthly mean SLP anomalies from NNR data (1958 to 2007), for time windows of $20 \mathrm{yr}$, each overlapping by $10 \mathrm{yr}$ (Fig. 4). The first EOF is well separated from subsequent modes, thus representing a robust pattern which can be associated with the NAO. The 4 periods demonstrate a change in the NAO pattern manifested by an eastward shift of the centers of action. A shift of the NAO centers of action between the periods P1 and P3 has been described previously by e.g. Hilmer \& Jung (2000) and Jung et al. (2003). Our extended EOF analysis confirms the persistent eastward shift during $\mathrm{P} 4$, which results in an increased influence of the NAO on northern Europe. The most pronounced shift of the centers of action occurs between P2 and P3, where both centers moved more than $15^{\circ}$ eastward. While between P3 and P4 the northern center of action is shifted another $20^{\circ}$ eastward, the southern center of action remains stationary. Over the periods P1 to P4 there is a continuous shift of the northern center of action to the northeast, implying an increased impact of NAO variability on the Baltic area. Furthermore, the SLP gradient over southern and northern Europe intensifies, leading to enhanced warm air advection from the North Atlantic to Europe, which results in mild winters and less ice coverage in the Baltic Sea area (compare with Figs. $2 \& 3$ ).

Following Hurrell \& Deser (2009), we performed a cluster analysis of winter (DJFM) daily mean SLP anomalies using NNR data for the period 1948 to 2009. The number of days in each winter (DJFM) season that represents a given regime during the $20 \mathrm{yr}$ periods ( $\mathrm{P} 1$, P2, P3, and P4) are shown in Table 1. The contribution of the Blocking and Atlantic Ridge pattern is between 48 and $50 \%$ for the considered time periods, and the total contribution of the NAO pattern is between 50 and $52 \%$. However, the relative contributions are different for the different periods (P1 to P4). For P1 and $\mathrm{P} 2$, the $\mathrm{NAO}^{-}$pattern prevails, whereas for $\mathrm{P} 3$ and $\mathrm{P} 4$, the $\mathrm{NAO}^{+}$pattern dominates.

In addition, wavelet spectra were used to examine the relationship between mean winter season (DJFM) 


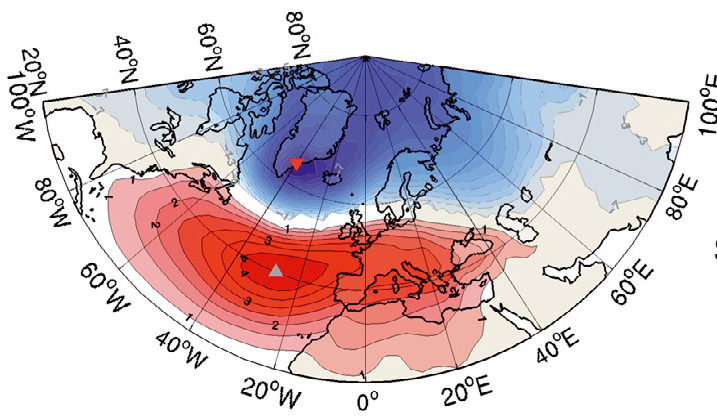

P1: 1958/59-1977/78

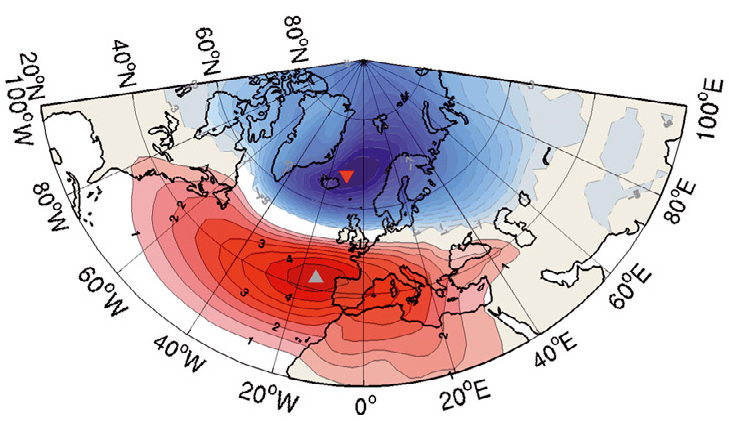

P3: 1978/79-1997/98

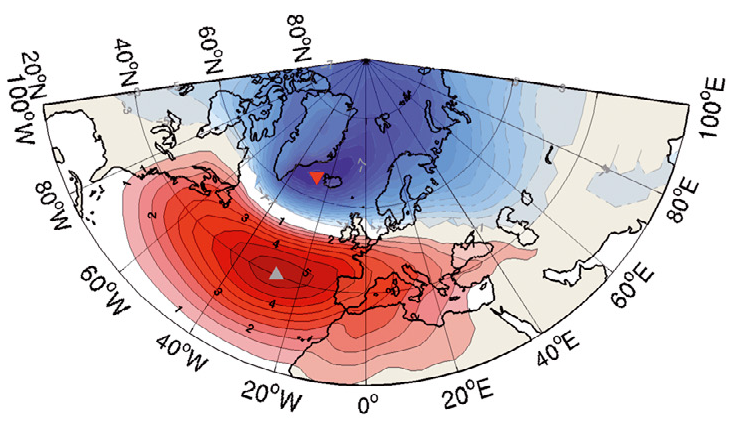

P2: $1968 / 69-1987 / 88$

0

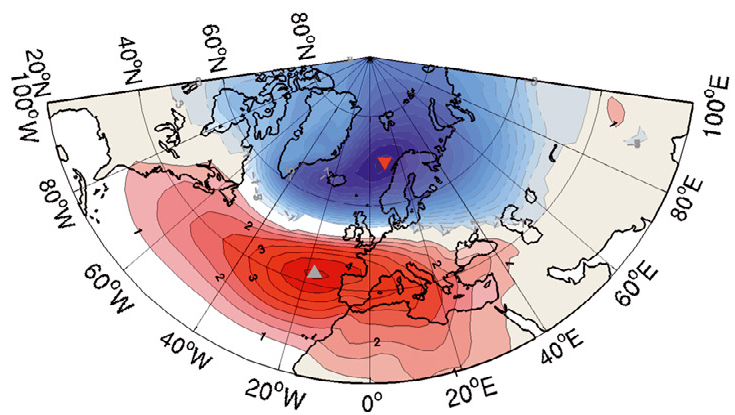

P4: $1988 / 89-2007 / 08$

Fig. 4. First empirical orthogonal function (EOF) of winter (DJFM) averaged monthly mean (scaled) North Atlantic sea level pressure (SLP) anomalies ( $\mathrm{hPa}$ ) from the NCEP/NCAR reanalysis data for periods P1 to P4. Positions of the centers of action are shown $(\Delta, \boldsymbol{\Delta})$. Explained variances of first EOF (second EOF) in chronological order: $44.9 \%(15 \%), 47 \%(14 \%), 52.8 \%(13 \%)$, and $47.8 \%$

$(16.6 \%)$. Contour interval is $0.5 \mathrm{hPa}$

air-temperature anomalies of $\mathrm{HT}$ and the NAO winter (DJFM) index over the frequency domain (Fig. 5). The wavelet analysis reveals a change in spectral characteristics (Fig. 5a,b). From the beginning of the 1960s, both spectra show higher-power estimates at about 8 yr. In the middle of the 1980s, a bifurcation to $9 \mathrm{yr}$ and 5 yr (even 3 yr around 1995) becomes apparent in both data sets. The cross wavelet transform between HT and the NAO index (Fig. 5c) indicates strong similarities in both power spectra for the frequency domain and the time period as well as for the phase angle (not shown), which is always uniformly directed in-phase. Here the common features we found by eye from the

Table 1. Contribution (\%) of occurrence of the $\mathrm{NAO}^{+}, \mathrm{NAO}^{-}$, Blocking, and Atlantic Ridge patterns in each $20 \mathrm{yr}$ period identified by cluster analysis using daily winter (DJFM) sea level pressure anomalies from NCEP/NCAR reanalysis data (1948 to 2009). NAO: North Atlantic Oscillation. P1: 19581977, P2: 1968-1987, P3: 1978-1997, P4: 1988-2007

\begin{tabular}{|lcccc|}
\hline & P1 & P2 & P3 & P4 \\
\hline NAO $^{+}$ & 22 & 23 & 30 & 34 \\
NAO $^{-}$ & 29 & 27 & 22 & 16 \\
Blocking & 27 & 28 & 27 & 28 \\
Atlantic Ridge & 22 & 22 & 21 & 22 \\
\hline
\end{tabular}

individual wavelet transforms stand out as being significant at the $95 \%$ level. For the whole time period, without any influence of edge effects, a significant power component at long time scales exists around an 8 yr period. Additionally, from the late 1980s to the late 1990s, a significant power component of about $5 \mathrm{yr}$ exists. Furthermore, 2 time periods of about 5 yr length exist with significant power at around $3 \mathrm{yr}$. This is in good agreement with results presented by Chen \& Hellström (1999). A similar structure in common features appears also in the wavelet spectra of the MIB (Grinsted et al. 2004, their Fig. 2). Jevrejeva et al. (2003) showed that the largest variances in MIB were in excellent agreement with significant power in the Arctic Oscillation at $2.2-3.5,5.7-7.8$, and $12-20 \mathrm{yr}$ periods. The strong similarity in both power spectra confirms the high correlation between NAO and corresponding winter temperature anomalies as well as with the MIB.

\subsection{Regional atmospheric variability}

Changes in large-scale atmospheric circulation should result in corresponding changes in the regional atmospheric variability of the Baltic Sea area. 

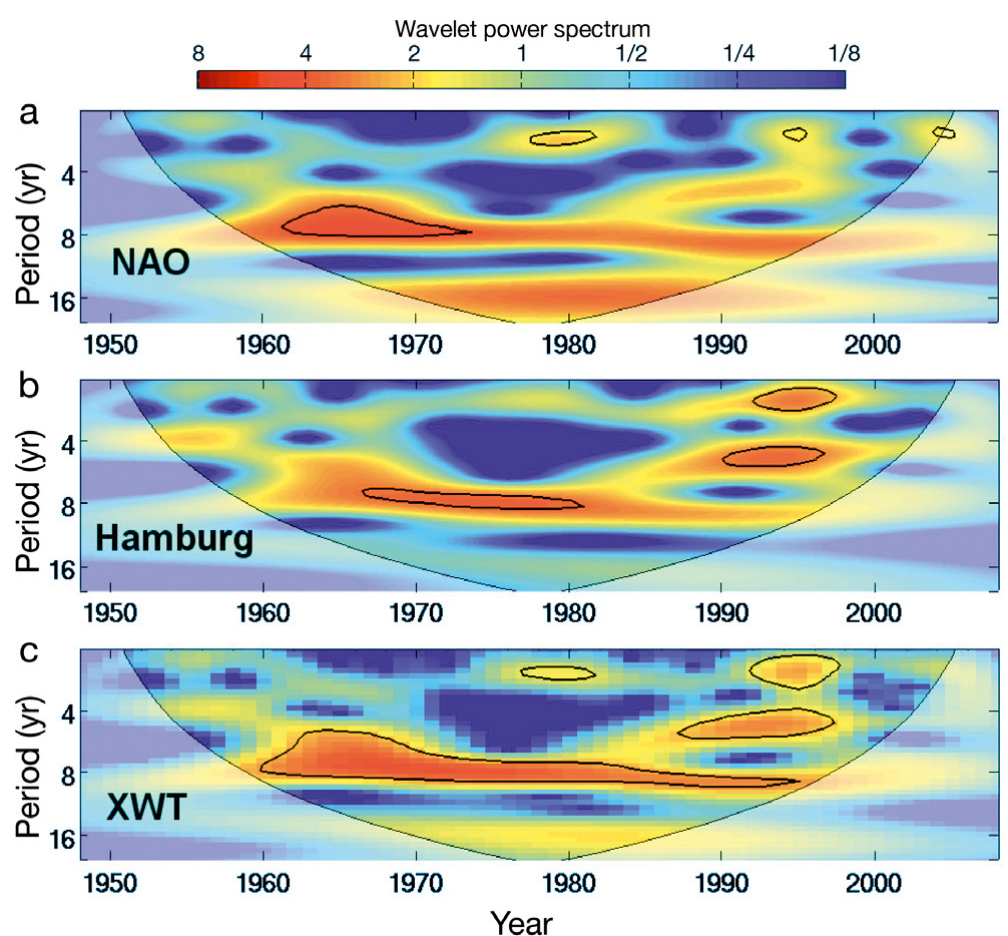

Fig. 5. Continuous wavelet power spectrum of standardized time series of winter (DJFM) (a) North Atlantic Oscillation (NAO) index or (b) daily mean surface air temperature at Hamburg-Fuhlsbüttel, Germany. (c) Cross wavelet transform (XWT) of time series in (a) and (b). Thick black contours designate the $95 \%$ significance level against red noise. The area outside the cone of influence, where edge effects might distort the picture, is shown by lighter shades

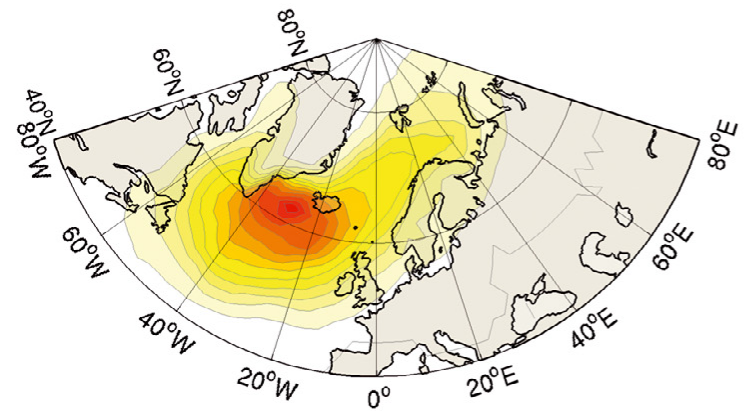

P1: $1958 / 59-1977 / 78$

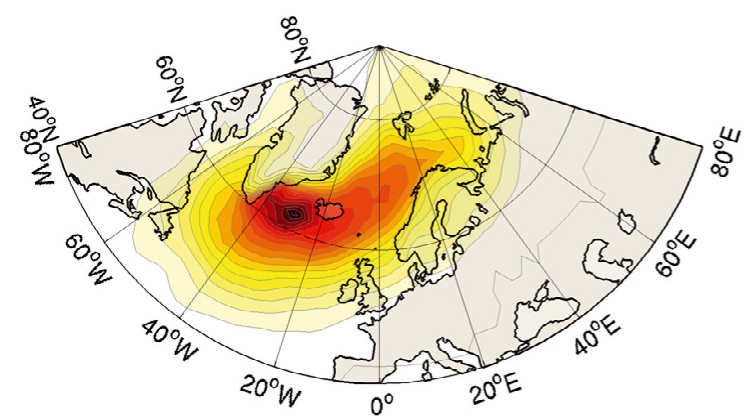

P3: $1978 / 79-1997 / 98$
It is well known that winters with a positive/negative NAO index are accompanied by changes in cyclone activity in the North Atlantic region (Hurrell 1995, Gulev et al. 2002). From the NNR SLP data, changes in the number and pathways of deep cyclones have been determined for the $20 \mathrm{yr}$ periods P1 to P4. We simply counted the occurrence of deep $(<980 \mathrm{hPa})$ cyclones at each grid point in a $6 \mathrm{~h}$ interval. With a horizontal resolution of $2.5^{\circ}$ of the SLP data, multiple counting of deep cyclones at one location is possible, which increased the number of deep cyclone occurrences. Fig. 6 shows the changes in the number of deep cyclones for winter (DJFM) counted for each $20 \mathrm{yr}$ period P1 to P4. The occurrence of deep cyclones over the North Atlantic region increases continuously from P2 to P4. Furthermore, for the first period the main occurrence of deep cyclones is concentrated in the northern North Atlantic between Greenland and Iceland. For the following periods the track of deep cyclones extends further to the northeast into the Arctic, with an increasing influence on northern Europe and the Baltic Sea area (Fig. 6). The northeast extension corresponds with the eastward shift and intensification of the SLP gradient of the

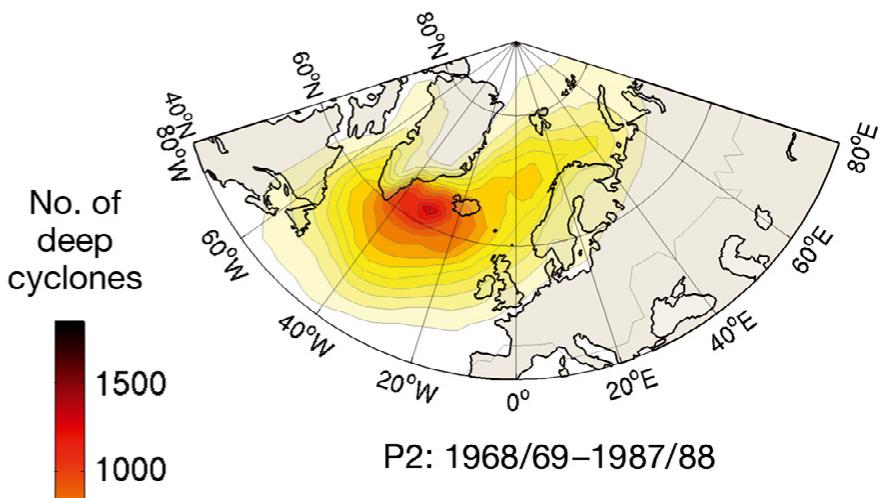

P2: 1968/69-1987/88

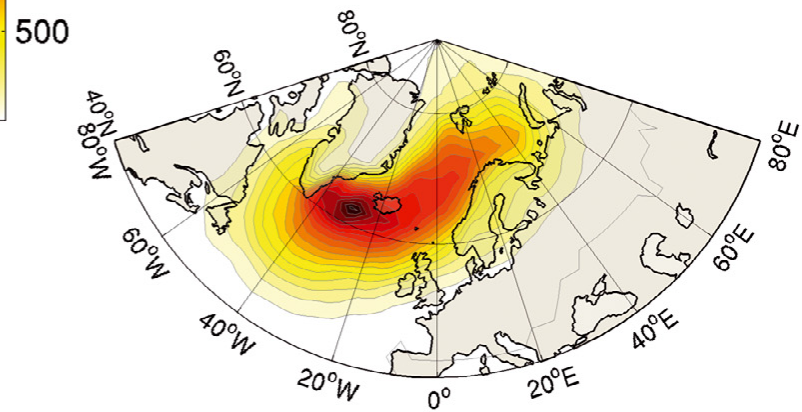

P4: $1988 / 89-2007 / 08$

Fig. 6. Total number of deep (<980 hPa) cyclones counted during each of the periods P1 to P4, based on NCEP/NCAR reanalysis 4 times daily sea level pressure data (winter, DJFM). Unit is number of deep cyclones, with an increment of 100 
dominant NAO pattern (Fig. 4). A more sophisticated method to detect and track cyclones has been presented by Wang et al. (2006). A cyclone detection/tracking algorithm was used to identify cyclones for 2 gridded $6 \mathrm{~h}$ mean SLP data sets: the 40 yr European Centre for Medium-Range Weather Forecasts (ECMWF) re-analysis (ERA-40), and the NNR for 1958 to 2001 (Wang et al. 2006). They investigated changes over 2 periods, 1958 to 1977 and 1982 to 2001, which nearly correspond to our P1 and P3, respectively, and found a small increasing trend in winter (JFM, i.e. January to March) strong-cyclone activity over northern Europe associated with a shift of the storm track over the North Atlantic by about $180 \mathrm{~km}$ northward, which agrees with our results.

The increasing number and eastward extension of the occurrence of deep cyclones during the winter season is also evident in the temporally and spatially higher-resolved SMHI meteorological data

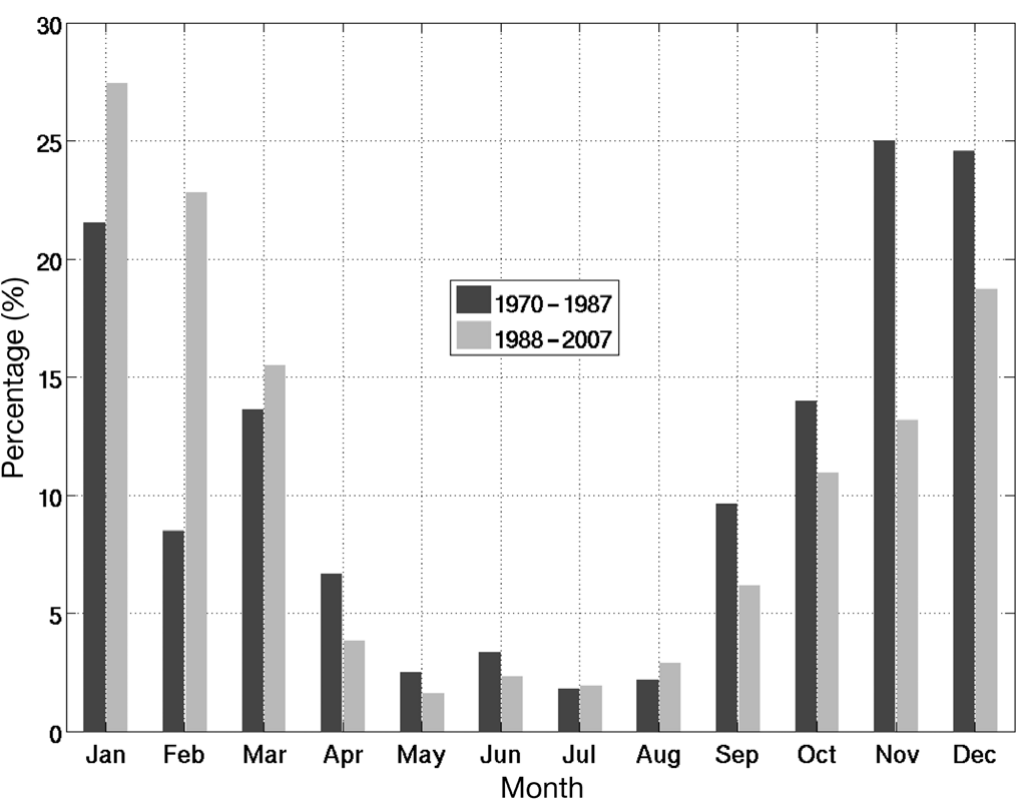

Fig. 7. Percentage of days with wind speeds $>13.9 \mathrm{~m} \mathrm{~s}^{-1}(>7$ on the Beaufort scale) for all months during the periods 1970-1987 and 1988-2007 at Lighthouse Kiel, in Kiel Bight, based on meteorological data from the Swedish Meteorological and Hydrological Institute

set (not shown). The analysis of the SMHI

data set shows that during spring (MAM, i.e. March to May), there exists a similar but weaker spatial extension of deep cyclones to the northeast, while during autumn (SON, i.e. September to November), the influence on the Baltic area even decreases. Changes in the pathways and frequency of deep cyclones affect the wind pattern over the Baltic area. Comparing the periods 1970 to 1988 and 1989 to 2007, winter (DJF, i.e. December to February) mean geostrophic wind increased by about $0.5 \mathrm{~m} \mathrm{~s}^{-1}$ for the northern and $1.5 \mathrm{~m}$ $\mathrm{s}^{-1}$ for the southern and central Baltic Sea. For spring (MAM), the geostrophic wind increased by 0.5 to $1 \mathrm{~m}$ $\mathrm{s}^{-1}$ over most parts of the Baltic Sea with a corresponding change in wind direction from southwest to west. During autumn (SON), the mean geostrophic wind decreased by about 1.5 to $2 \mathrm{~m} \mathrm{~s}^{-1}$ for the western and central and $0.5 \mathrm{~m} \mathrm{~s}^{-1}$ for the northern parts of the Baltic Sea (not shown). Analysis of wind-speed data of the SMHI meteorological database interpolated to the position Lighthouse Kiel revealed a shift of strong wind events from autumn to winter and early spring. Fig. 7 shows this shift for days with wind speeds $>13.9 \mathrm{~m} \mathrm{~s}^{-1}$ ( $>7$ on the Beaufort scale) for the periods 1970 to 1987 and 1988 to 2007. Furthermore, the frequency distribution of wind directions highlights a decrease of southwesterly winds in autumn (SON) accompanied by an increase of easterly winds (Fig. 8a), whereas during winter (DJF), the number of westerly wind events increased, while at the same time easterly wind situations decreased (Fig. 8b). Keevallik \& Soomere (2008) observed a shift in the early-spring wind regime over the northeastern Baltic area. They concluded that multiple regime shifts in the wind components happened between different periods (PKS1: 1955-1966, PKS2: 1967-1995, PKS3: 1996-2007), especially pronounced in March. The shift from southwest to west-southwest between PKS2 and PKS3 in this area is also evident in our analysis, although the periods analyzed here do not completely match.

The period 1970 to 2008 (SMHI meteorological data set) exhibits a warming trend in the annual mean SAT of $0.4^{\circ} \mathrm{C}$ decade ${ }^{-1}$ or larger, particularly over the Baltic Sea (Fig. 9). It is interesting to note that the strongest warming, $>0.5^{\circ} \mathrm{C}$ decade $^{-1}$, occurs in the northern Baltic Sea. The seasonal contribution to the annual surface temperature trend is strongest in the Gulf of Bothnia during autumn and winter at 0.5 to $0.6^{\circ} \mathrm{C} \mathrm{decade}^{-1}$, while during spring and summer the significant contribution is strongest in the central and southern part of the Baltic Sea at 0.3 to $0.4^{\circ} \mathrm{C} \mathrm{decade}^{-1}$ (not shown). The trend in annual mean SST (Fig. 10), derived from infrared satellite images (1990 to 2008), reflects the trend in SAT (Fig. 9). For the northern parts of the Baltic Sea, a warming of 0.8 to $1^{\circ} \mathrm{C}$ decade $^{-1}$ is seen, with the highest values in the Gulf of Bothnia and the Gulf of Finland. For the central part, a warming of 0.5 to $0.9^{\circ} \mathrm{C}$ decade ${ }^{-1}$ has been determined. It is interesting to note that the smallest trends occur along the east coast of Sweden $\left(0.3\right.$ to $0.5^{\circ} \mathrm{C}$ decade $\left.^{-1}\right)$, which most probably is a result due to upwelling in this area. 

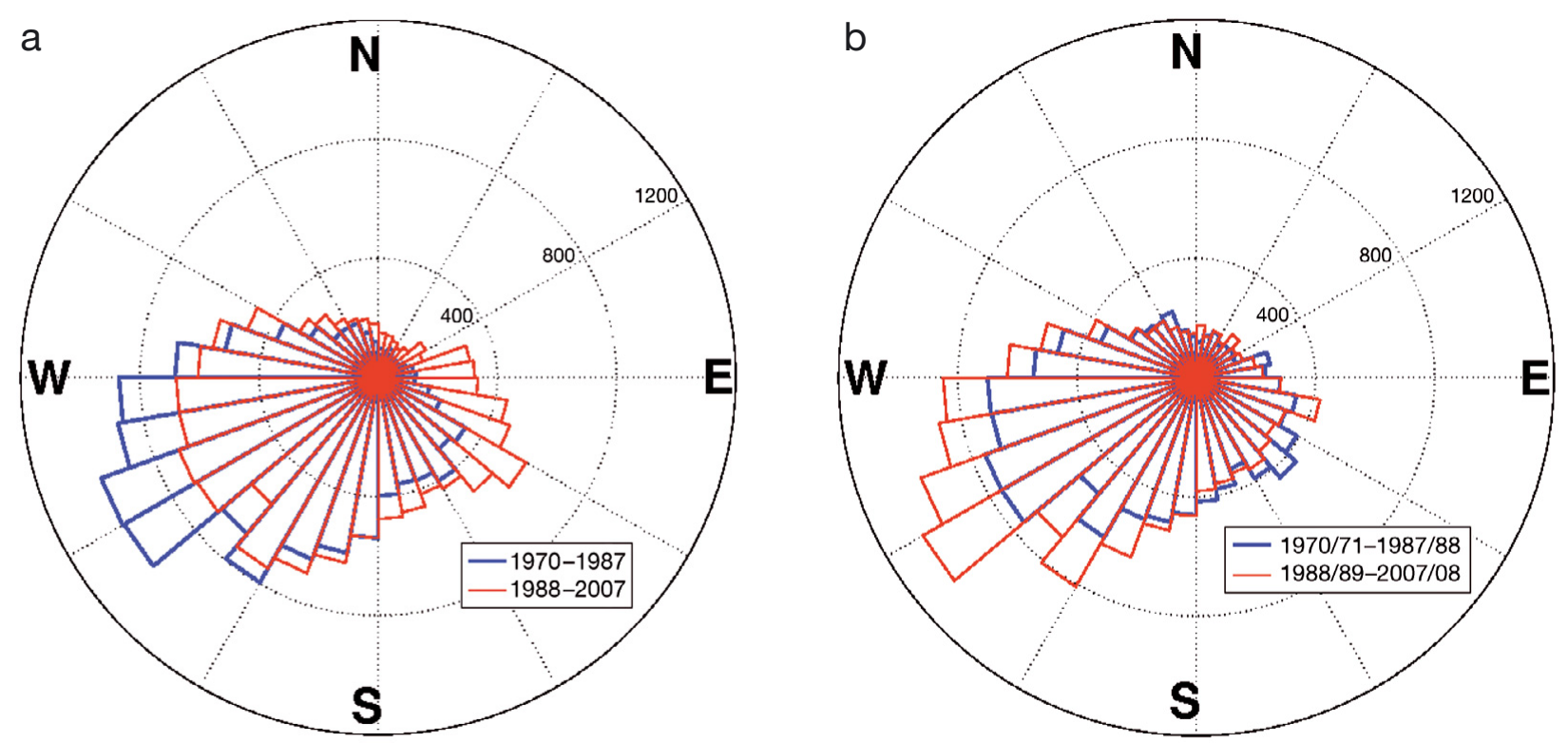

Fig. 8. Frequency distribution of wind direction during the periods 1970 to 1987 (blue) and 1988 to 2007 (red) at Lighthouse Kiel, in Kiel Bight, based on meteorological 3-hourly data from the Swedish Meteorological and Hydrological Institute. (a) Seasonal autumn (SON); (b) seasonal winter (DJF)

Either the water below the thermocline is less affected by the atmospheric warming trend (Hinrichsen et al. 2007), which leads to a smaller warming trend at the sea surface, or a shift of the dominant wind direction leads to increased upwelling.

In line with the warming trend, there is a trend to less cloud cover over the Baltic Sea Basin including Finland (on average $-1 \%$ decade $^{-1}$; Fig. 11 ), with sea-

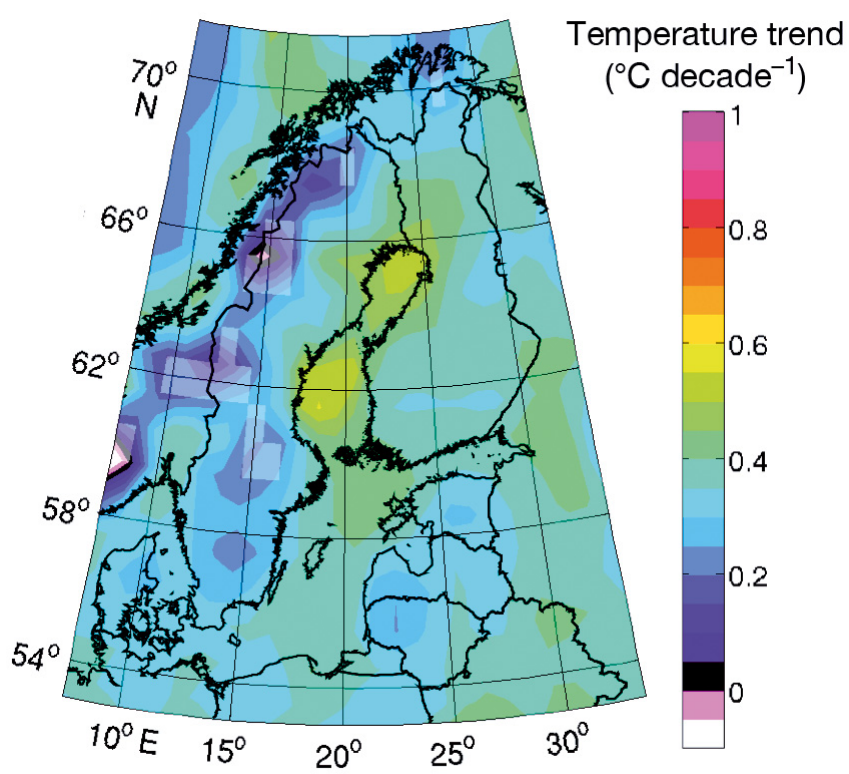

Fig. 9. Linear trend of the annual mean surface air temperature based on meteorological data (1970 to 2008) from the Swedish Meteorological and Hydrological Institute. Light-shaded areas are not statistically significant with $95 \%$ confidence sonal contributions mainly during spring and autumn. Increasing cloud cover can be detected for those parts of Scandinavia that are exposed to westerlies, the Kola peninsula and southeast from the Gulf of Finland, which is mostly due to seasonal contributions during winter and summer. The trend in annual precipitation for the period 1979 to 2008 is less rain in the central and northern areas (2 to $4 \mathrm{~mm} \mathrm{yr}^{-1}$ ) of the Baltic Sea

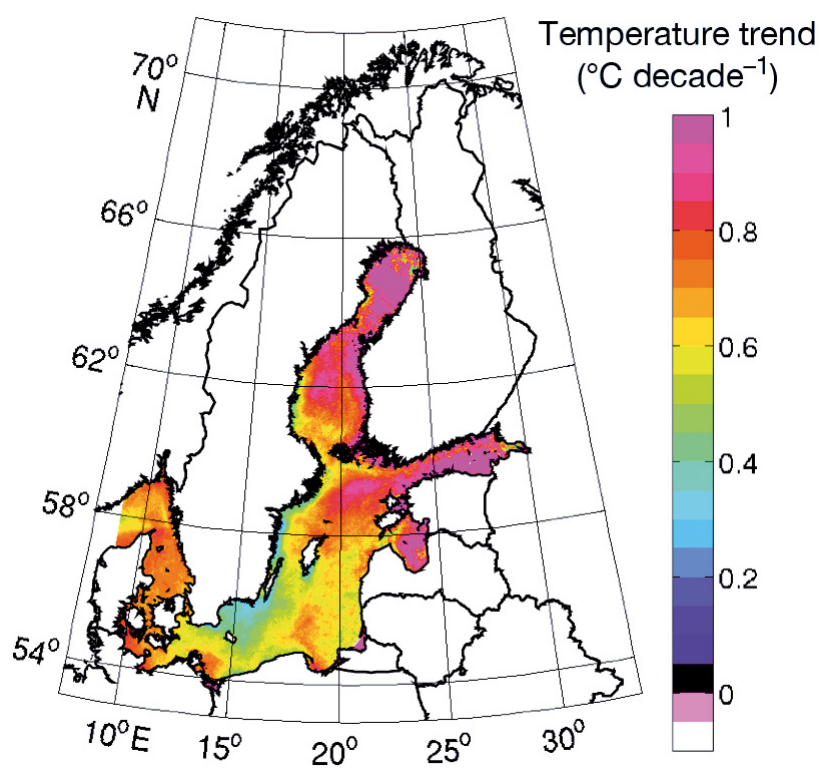

Fig. 10. Linear trend of the annual mean sea surface temperature based on infrared satellite data (1990 to 2008) provided by the Federal Maritime and Hydrographic Agency (BSH), Hamburg 


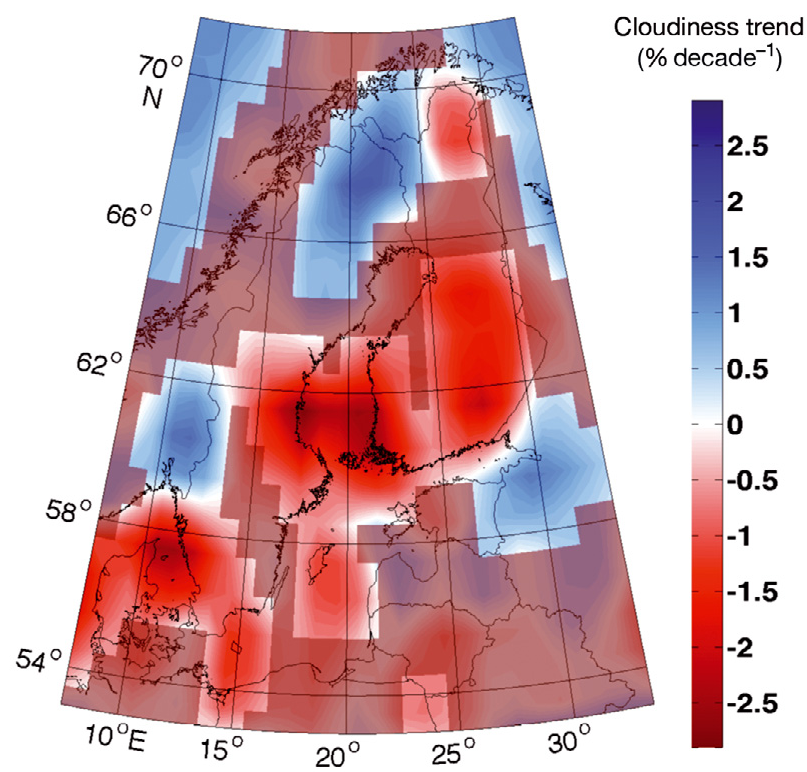

Fig. 11. Linear trend of cloudiness based on meteorological data (1970 to 2008) from the Swedish Meteorological and Hydrological Institute. Dark shaded areas are not statistically significant with $95 \%$ confidence

Basin and an increase of the same order in the southern part (not shown). Because trends for the seasonal contributions were not always significant within a $95 \%$ confidence level, we considered the difference in precipitation by dividing the period into equal parts (1979 to 1993 and 1994 to 2008) and restricted the analysis to be only qualitative (Fig. 12). Generally, winter (DJF) saw less rain over most parts of the Baltic Sea Basin and the leeward side of the Scandinavian Mountains, except over Finland and the Kola Peninsula. Spring (MAM) had more rain in the southern part and less rain for the northern Baltic Sea including most parts of Sweden. Summer (JJA, i.e. June to August) showed more rain in the southwest and less in the northeast, and autumn (SON) saw less rain over the northern Baltic Sea including Sweden and more rain in the southwestern part of the Baltic area, respectively. There were regions where the change in precipitation between the 2 periods was unidirectional for all seasons. The central and northern part of Sweden and the northern Baltic Sea Basin, respectively, contributed with less rain throughout all seasons, which is in good agreement with the negative trend in cloud cover (Fig. 11), and the stronger positive trend in annual mean SAT and SST (Figs. 9 \& 10). In contrast, there was an increase in precipitation in the southwestern part of the Baltic Sea Basin (Fig. 12) during spring (MAM), summer (JJA), and autumn (SON), and it was not accompanied by an increase in cloudiness. This could be an indicator for an intensification of precipitation events.

\section{DISCUSSION AND CONCLUSIONS}

From cluster analysis of North Atlantic SLP (1950 to 2006), Hurrell \& Deser (2009) identified 4 winter climate regimes that all occurred with about the same frequency ( 20 to $30 \%$ of all winter days, DJFM). There is evidence for spatial asymmetries in the position of the pressure anomalies of positive and negative NAO phases, in particular an eastward shift $\left(\sim 30^{\circ}\right.$ longitude) and northeastward extension of the subpolar SLP anomalies in the positive regime relative to the negative one (Cassou et al. 2004). Longitudinal shifts in the center of action could thus arise from the preferential excitement of positive NAO regimes, which are intrinsically displaced eastward, rather than a shift of the centers of actions (see Hurrell \& Deser 2009 for a detailed discussion). Ulbrich \& Christoph (1999) found a similar shift of the NAO under increasing greenhouse gas forcing in a coupled global climate model simulation. Hilmer \& Jung (2000) documented an eastward shift of the centers of interannual NAO variability over the period $\mathrm{P} 1$ relative to $\mathrm{P} 3$. They postulated that such a change was due to different modes of the NAO pattern. Our analysis confirms this eastward shift of the NAO pattern. Furthermore, our extended analysis (until 2008) proves that the centers of action remain in the eastward positions and have not yet switched back. Following Hurrell \& Deser (2009), the eastward position of the NAO pattern is probably due to the prevailing strong positive NAO winter indices for the recent 20 yr period. Hurrell \& Deser (2009) stressed that most winter seasons (DJFM) are not dominated by only one particular pattern, and that although the NAO is the dominant pattern of atmospheric circulation variability over the North Atlantic, it explains only a fraction of the total variance. Thus, most winters cannot be characterized solely by the canonical NAO pattern. However, considering 20 yr periods, the first EOF explains about 40 to $50 \%$ of the total SLP variance, and thus the first EOF can be used to characterize the temporal evolution of the dominant pattern of the largescale atmospheric circulation over the North Atlantic. The cluster analysis of winter (DJFM) daily mean SLP anomalies using NNR data for the period 1949 to 2009 revealed that the relative contributions of the 4 clusters $\left(\mathrm{NAO}^{+}, \mathrm{NAO}^{-}\right.$, Blocking, and Atlantic Ridge) varied over the considered time periods (P1 to P4; Table 1). For P1 and $\mathrm{P} 2$, the $\mathrm{NAO}^{-}$pattern prevailed, whereas for $\mathrm{P} 3$ and $\mathrm{P} 4$ the $\mathrm{NAO}^{+}$pattern dominated. Thus, the shift of the centers of actions resulting from the EOF analysis is in agreement with the results of the cluster analysis.

The detailed assessment of climate variability of the Baltic Sea area for the period 1958 to 2009 revealed that the recent changes in the warming trend are associated with changes in the large-scale atmospheric 

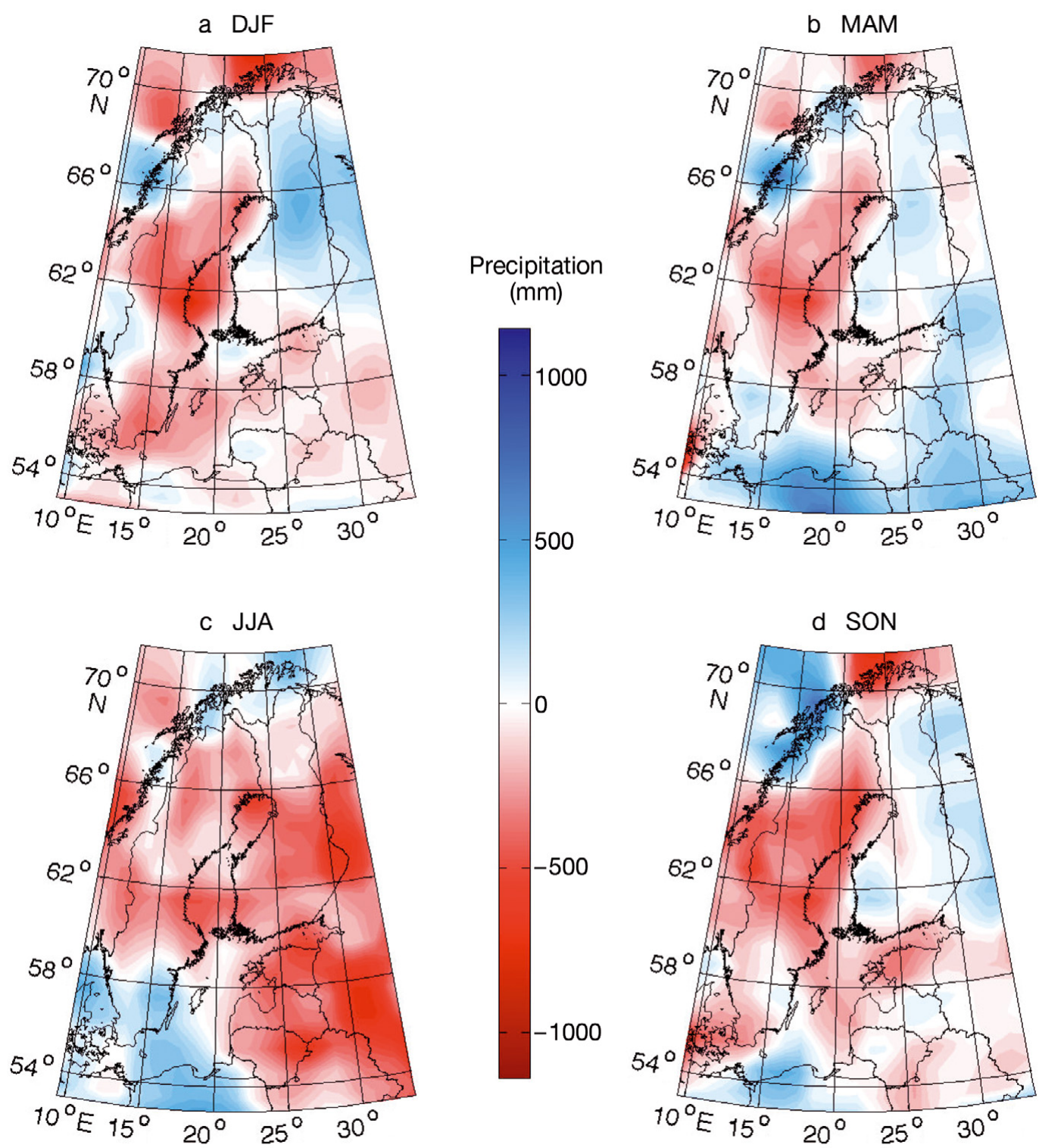

Fig. 12. Seasonal differences (a: winter, b: spring, c: summer, d: autumn) in precipitation between 2 periods of equal length, 1979 to 1993 and 1994 ot 2008, based on meteorological data from the Swedish Meteorological and Hydrological Institute

circulation over the North Atlantic. In line with these changes, there is a variation in the spectral characteristics of the NAO index to shorter periods, which is well established in the corresponding temperature records for HT. Furthermore, number and pathways of deep cyclones changed considerably in parallel with the eastward shift of the NAO centers of action. For the Baltic area there exists a seasonal shift of strong wind events from autumn to winter and early spring. Furthermore, we demonstrated that since 1987 the winter season (DJFM) of the Baltic Sea area has tended to be warmer, with less ice coverage and warmer SST, especially pronounced in the northern parts of the Baltic Sea. The picture is less clear for changes in cloudiness and precipitation. Although atmospheric processes have a governing role, orography greatly influences spatial distribution and intensity of precipitation. Additionally, poor data-coverage and improved techniques for measuring precipitation make accurate estimation of precipitation trends difficult (BACC Author Group 2008). However, there is a tendency during the cold season towards increased cloud cover and precipitation in regions that are exposed to humid westerlies, and less cloud coverage at the leeward side of the Scandinavian Mountains and over the Baltic Sea Basin. The somewhat contradictory situation over Finland with a decreasing trend in cloud cover but increasing precipitation could be due to the increased number of deep 
cyclones, which simultaneously leads to less highpressure situations, in which during wintertime the sky is mostly cloud-covered, whereas there is less cloudiness behind the cold front of low-pressure systems.

Using different data sets results in the challenge of combining various spatio-temporal resolutions. The use of heterogeneous data sets, which are consistent with respect to the method used to derive them and their associated quality control, is a strength of the present study, giving consistent results for independent parameters. These publicly available data sets, which include data from the Baltic Sea area, are mainly used for validation and forcing of regional atmosphereocean models as well as regional climate models. Future work will include the analysis of climate variability using additional data sets such as ERA-40 and ERA-Interim as well as corresponding data from regional climate model simulations driven by reanalysis data and climate change scenarios.

Acknowledgments. We acknowledge the German Weather Service (DWD) for providing us with long-term surface air temperature records from Hamburg-Fuhlsbüttel and the Finnish Meteorological Institute (FMI) for their sea-ice data set. This work was supported by the Technical University of Denmark (DTU), the BONUS+ project BalticWay (financed by the Federal Ministry of Education and Research, BMBF) and by the Kiel Cluster of Excellence 'The Future Ocean' (German Research Foundation, DFG).

\section{LITERATURE CITED}

BACC Author Group (2008) Assessment of limate change for the Baltic Sea Basin. Springer-Verlag, Berlin

- Cassou C, Terray L, Hurrell JW, Deser C (2004) North Atlantic winter climate regimes: spatial asymmetry, stationarity with time, and oceanic forcing. J Clim 17:1055-1068

Chen D, Hellström C (1999) The influence of the North Atlantic Oscillation on the regional temperature variability in Sweden: spatial and temporal variations. Tellus A 51:505-516

Dommenget D, Latif M (2002) A cautionary note on the interpretation of EOFs. J Clim 15:216-225

> Grinsted A, Jevrejeva S, Moore J (2004) Application of the cross wavelet transform and wavelet coherence to geophysical time series. Nonlinear Process Geophys 11:561-566

> Gulev SK, Jung T, Ruprecht E (2002) Climatology and interannual variability in the intensity of synoptic scale processes in the North Atlantic from the NCEP-NCAR reanalysis data. J Clim 15:809-828

Hilmer M, Jung T (2000) Evidence for a recent change in the link between the North Atlantic Oscillation and Arctic Sea ice export. Geophys Res Lett 27:989-992 doi:10.1029/ 1999GL010944

Hinrichsen HH, Lehmann A, Petereit C, Schmidt J (2007) Correlation analysis of Baltic Sea winter water mass formation and its impact on secondary and tertiary production. Oceanologia 49:381-395

Hurrell JW (1995) Transient eddy forcing of the rotational flow during northern winter. J Atmos Sci 52:2286-2301
Hurrell JW, Deser C (2009) North Atlantic climate variability: the role of the North Atlantic Oscillation. J Mar Syst 78: $28-41$

> Hurrell JW, van Loon H (1997) Decadal variations in climate associated with the North Atlantic Oscillation. Clim Change 36:301-326

Jevrejeva S, Moore JC, Grinsted A (2003) Influence of the Arctic Oscillation and El Niño-Southern Oscillation (ENSO) on ice conditions in the Baltic Sea: the wavelet approach. J Geophys Res Atmos 108:4677 doi:10.1029/ 2003JD003417

> Jones PD, Jonsson T, Wheeler D (1997) Extension to the North Atlantic Oscillation using early instrumental pressure observations from Gibraltar and south-west Iceland. Int J Climatol 17:1433-1450

> Jung T, Hilmer M, Ruprecht E, Kleppek S (2003) Characteristics of the recent eastward shift of interannual NAO variability. J Clim 16:3371-3382

Kalnay E, Kanamitsu M, Kistler R, Collins W and others (1996) The NCEP/NCAR 40-year reanalysis project. Bull Am Meteorol Soc 77:437-470

> Keevallik S, Soomere T (2008) Shifts in early spring wind regime in north-east Europe. Clim Past 4:147-152

> Koslowski G, Glaser R (1999) Variations in reconstructed ice winter severity in the western Baltic from 1501 to 1995, and their implications for the North Atlantic Oscillation. Clim Change 41:175-191

Koslowski G, Loewe P (1994) The western Baltic Sea ice season in term of mass related severity index 1879-1992. I. Temporal variability and association with the North Atlantic Oscillation. Tellus A 46:66-74

Lehmann A, Krauss W, Hinrichsen HH (2002) Effects of remote and local atmospheric forcing on circulation and upwelling in the Baltic Sea. Tellus A 54:299-316

Leppäranta M, Myrberg K (2009) Physical oceanography of the Baltic Sea. Springer-Verlag, Berlin

MacKenzie BR, Schiedek D (2007) Daily ocean monitoring since the 1860s shows record of warming northern European seas. Glob Change Biol 13:1335-1347

> North GR, Bell TL, Cahalan RF, Moeng FJ (1982) Sampling errors in the estimation of empirical orthogonal functions. Mon Weather Rev 110:699-706

> Omstedt A, Chen D (2001) Influence of atmospheric circulation on the maximum ice extent in the Baltic Sea. J Geophys Res 106:4493-4500 doi:10.1029/1999JC000173

Rudolph C, Lehmann A (2006) A model-measurements comparison of atmospheric forcing and surface fluxes of the Baltic Sea. Oceanologia 48:333-360

Rutgersson A, Bumke K, Clemens M, Foltescu V, Lindau R, Michelson D, Omstedt A (2001) Precipitation estimates over the Baltic Sea: present state of the art. Nord Hydrol 32:285-314

Seinä A, Palosuo E (1996) The classification of the maximum annual extent of ice cover in the Baltic Sea 1720-1995. Meri Rep Ser Finn Inst Mar Res 20:79-91

Siegel H, Gerth M, Tschersich G (2006) Sea surface temperature development of the Baltic Sea in the period 19902004. Oceanologia 48:119-131

Tinz B (1996) On the relation between annual maximum extent of ice cover in the Baltic Sea and sea level pressure as well as air temperature field. Geophysica 32:319-341

- Torrence C, Compo GP (1998) A practical guide to wavelet analysis. Bull Am Meteorol Soc 79:61-78

Trenberth KE, Jones PD, Ambenje P, Bojariu R and others (2007) Observations: surface and atmospheric climate change. In: Solomon S, Qin D, Manning M, Chen Z and 
others (eds) Climate change 2007: the physical science basis. Contribution of Working Group I to the Fourth Assessment Report of the Intergovernmental Panel on Climate Change. Cambridge University Press, Cambridge, p 241-253

Ulbrich U, Christoph M (1999) A shift of the NAO and increasing storm track activity over Europe due to anthropogenic greenhouse gas forcing. Clim Dyn 15:551-559

Vainio J, Isemer HJ (2008) Mildest ice winter ever in the

Editorial responsibility: Eduardo Zorita, Geesthacht, Germany
Baltic Sea. BALTEX Newsl 11:6-7 www.baltex-research. eu/publications/newsletter.html

Wallace JM, Gutzler DS (1981) Teleconnections in the geopotential height field during the northern hemisphere winter. Mon Weather Rev 109:784-812

Wang XL, Swail VR, Zwiers FW (2006) Climatology and changes of extratropical cyclone activity: comparison of ERA-40 with NCEP-NCAR reanalysis for 1958-2001. J Clim 19:3145-3166

Submitted: November 9, 2009; Accepted: May 12, 2010 Proofs received from author(s): December 10, 2010 